\title{
The effects of differential acquisition-stage emphasis and auto-instructions upon verbal mediating responses'
}

MARGARET JEAN PETERSON AND SARAH D. HILLNER INDIANA UNIVERSITY

Mediated responding was studied as a function of the "emphasis" given to the acquisition-stage items. Mediated responding was evinced when $S$ s reported that they had attempted to consider the acquisition pairs while making their choice on the test trial. The greatest evidence of mediated facilitation was obtained when all stimulus items of the acquisition pairs and when the critical response term were emphasized during the acquisition stages.

If the performance on the third or test stage of a three-stage mediation set (B-C, B-A, A-CDE) differs reliably from performance on the third or test stage of a three-stage control set (X-C, B-A, A-CDE), mediated responding may be inferred. Mediated responding apparently is fostered by correct retention of the acquisition pairs for at least $2 \mathrm{sec}$. (Peterson, 1965). It seems reasonable to assume that a condition conducive to the correct retention of the acquisition pairs might enhance mediated responding on the test trials.

Such a condition might arise if the distinctiveness of the members of the acquisition pairs were increased. A number of studies (e.g., Erickson, 1965; Saltz \& Newman, 1959) have indicated that distinctive (isolated, emphasized) items are more likely to be recalled correctly than less-distinctive items.

The experiments presented herein varied the distinctiveness of the items in various positions within the acquisition pairs by printing some items in red and some in black. Six different variations of the color of ink (the "emphasis"-conditions) were used, as schematized in Table 1.

\section{Method}

The within-S design called for comparison of mediation and control "sets" printed to correspond to the six emphasis-conditions (Black, C, A, CA, B, and B*). To control the learning materials appearing in each condition, 72 basic mediation sets were constructed. The sets were composed of CVCs (87-100\% association value, Underwood \& Schulz, 1960), chosen to minimize letter overlap. The actual paradigm for the mediation sets was $B-C, B, B-A, B, A-C D E$. Each set began with a pair of trigrams, B-C. The stimulus term, $B$, was then shown alone as a cue-trial to test retention of the preceding pair. The stimulus trigram from the first pair was then presented with another trigram, B, followed as the cue-trial to test retention of the second pair. Finally, the test trial was presented. It showed the response trigram from the second pair, $A$, as the stimulus for three response alternatives, including the response term from the first acquisition pair, $C$.

The $\mathrm{C}$ trigram appeared equally often in the first, second, and third position among the response alternatives on the test trials. To equate frequency of experience with the test-trial alternatives over all experimental sets, the D and E trigrams for a particular set were trigrams used as the $\mathrm{C}$ trigram in other sets.

The 72 mediation sets were printed on $4 \times 6$ in. index cards, using black ink. These sets represented the black emphasis-condition of mediation sets. The black form of the control sets was constructed by substituting a new, extraneous trigram for Stimulus $B$ in the first stage pair, $\mathrm{X}-\mathrm{C}$, and then printing the control sets with

Table 1. The Experimental Paradigms and the Mean Selections of $C$ on Test Trials

\begin{tabular}{|c|c|c|c|c|c|c|c|c|c|c|c|c|}
\hline Type of Presentation & Mediatio & & & & & & Control & & & & & \\
\hline Acquisition-Stage Emphasis & $\mathrm{C}$ & A & $\mathrm{CA}$ & $\mathrm{B}$ & $\mathrm{B}^{*}$ & Black & $\mathrm{C}$ & A & $\mathrm{CA}$ & $\mathrm{B}$ & $\mathrm{B}^{*}$ & Black \\
\hline First Stage & $\mathrm{B}-\mathrm{C}$ & $\mathrm{B}-\mathrm{C}$ & $\mathrm{B}-\mathrm{C}$ & $B-C$ & $B-\mathrm{C}$ & B-C & $\mathrm{x}-\mathrm{C}$ & $\mathrm{X}-\mathrm{C}$ & $\mathrm{X}-\mathrm{C}$ & $X-\mathrm{C}$ & $X-\mathrm{C}$ & $\mathrm{X}-\mathrm{C}$ \\
\hline Retention Test & B & B & $\mathrm{B}$ & $B$ & B & B & $\mathrm{x}$ & $\mathrm{x}$ & $\mathrm{x}$ & $x$ & $\mathrm{x}$ & $\mathrm{x}$ \\
\hline Second Stage & B-A & $\mathrm{B}-\mathrm{A}$ & $\mathrm{B}-\mathrm{A}$ & $B-A$ & $B-A$ & B-A & B-A & $\mathrm{B} \cdot A$ & $\mathrm{~B}-A$ & $B-A$ & $B-A$ & B-A \\
\hline Retention Test & $\mathrm{B}$ & B & $\mathrm{B}$ & $B$ & B & B & B & B & B & $B$ & B & B \\
\hline Test Stage & $\mathrm{A}-\mathrm{CDE}$ & $\mathrm{A}-\mathrm{CDE}$ & $\mathrm{A}-\mathrm{CDE}$ & $\mathrm{A}-\mathrm{CDE}$ & $\mathrm{A}-\mathrm{CDE}$ & $\mathrm{A}-\mathrm{CDE}$ & $\mathrm{A}-\mathrm{CDE}$ & $\mathrm{A}-\mathrm{CDE}$ & A-CDE & $\mathrm{A}-\mathrm{CDE}$ & A-CDE & $\mathrm{A}-\mathrm{CDE}$ \\
\hline $\begin{array}{l}\text { Mean Selections of C on Test } \\
\text { Means, Summed over all }\end{array}$ & rials & & & & & & & & & & & \\
\hline strategies & 3.72 & 3.72 & 3.45 & 3.47 & 3.45 & 3.53 & 3.23 & 3.60 & 3.58 & 3.42 & 3.37 & 3.33 \\
\hline $\begin{array}{l}\text { Means for Auto-instruction Gro } \\
\text { Strategy of selecting previous }\end{array}$ & & & & & & & & & & & & \\
\hline response (SPR) & 5.04 & 4.83 & 5.13 & 5.00 & 4.91 & 4.91 & 4.57 & 4.61 & 4.83 & 4.52 & 4.74 & 4.52 \\
\hline Individualistic strategies (IR) & 2.89 & 3.03 & 2.41 & 2.51 & 2.54 & 2.68 & 2.41 & 2.98 & 2.81 & 2.73 & 2.51 & 2.59 \\
\hline
\end{tabular}


black ink on the index cards. The paradigm for an entire control set was schematized as X-C, X, B-A, B, A-CDE. Next, the 72 mediation and their 72 control sets were printed to conform to the five other conditions of emphasis as shown in Table 1. Items appearing in the italicized positions were printed red; items in all other positions were printed in black. All test-trial materials were printed in black.

Each $S$ was exposed to one form of each of the 72 experimental sets. The 12 cells formed by the 6 emphasis-conditions and the 2 types of sets (mediation and control) were each represented 6 times among the 72 sets assigned to an S. Twelve orders of randomized presentation of the sets were established. The Ss were randomly assigned to the 12 orders with the restriction that five Ss experience each order.

The Ss were 60 introductory psychology students at Indiana University, 35 men and 25 women, who participated to fulfill a course requirement.

The five cards representing a set were shown successively before the first card of the next set was presented. The S spelled all trigrams. When the stimulus appeared alone, $\mathrm{S}$ spelled the trigram shown and then attempted to spell the trigram which had justbeen paired with the stimulus. If he erred the pair was presented again, then the stimulus was shown alone, and so on until $S$ responded correctly to the stimulus alone. On the test trials, S read the stimulus with each of the response alternatives and then stated which of the response alternatives "seemed right" or made the "best pair" with the stimulus.

After the experimental sets hadbeen presented, Swas asked, "How did you decide which response to select on the presentations with four syllables?" and dismissed. Results

Most of the acquisition pairs (99.79\%) were retained correctly until their cue trials. The errors that did occur were usually given on cue trials testing the second acquisition pairs, particularly those of mediation sets. Errors were not related to emphasis-conditions.

Primary interest was in the evidence of mediated responding on test-trials of sets representing the six emphasis-conditions. Mediated responding was evaluated by comparing the selections of $\mathrm{C}$ on the test trials of mediation sets with the selections of $\mathrm{C}$ on the test trials of control sets (Row 6, Table 1), and was found to be statistically significant with the $\mathrm{C}$ emphasis-condition only, $t=2.54, \mathrm{df}=240, \mathrm{p}<.05$ 。

The responses to the post-experimental query suggested that on the test trials some Ss attempted to select the response they had seen during the acquisition stages whereas other Ss used idiosyncratic strategies including the deliberate rejection of items previously experienced. Consequently, two categories of strategies governing test-trial choices were established: selecting the previous response (SPR) and individualistic re- sponses (IR). Two judges independently assigned $\mathrm{Ss}$ to these categories with $100 \%$ agreement. Subsequent statistical analyses corrected for unequal $n$ 's. The SPR Ss selected the $\mathrm{C}$ alternative more often than the IR Ss, $\mathrm{F}=48.16, \mathrm{df}=1 / 58, \mathrm{p}<.01$ 。

Mediated responding was evinced for all conditions of acquisition-stage emphasis by the SPR group, $F=4.60$, $\mathrm{df}=1 / 22, \mathrm{p}<.05$, but some emphasis-conditions yielded greater evidence of mediation than others (Row 7 , Table 1). Individual comparisons were made using t-tests. The indices of the $\mathrm{B}$ and $\mathrm{C}$ emphasis-conditions were significantly above those of the Black and CA emphasis-conditions. The indices of the $A$ and $B^{*}$ emphasis-conditions were below the others. The IR group did not provide statistically significant evidence of mediational responding (Row 8 , Table 1 ).

\section{Discussion}

Apparently, the emphasis-conditions interacted with the self-assigned strategies to determine mediational responding. Mediated responding was obtained when Ss reported that they had attempted to select, on the test trials, the response shown during the acquisition stages and the execution of these auto-instructions was facilitated by the emphasis of all stimulus terms or of the $\mathrm{C}$ term during acquisition.

These results favor the contention that mediational processes involve "conscious" attention to their use (cf., Martin \& Dean, 1964; Stein, 1966) rather than the view that mediation occurs "unconsciously" (cf., Bugelski \& Scharlock, 1952; Russell \& Storms, 1955; Peterson, 1963). However, the strategy-analysis was post-hoc so that its results must be considered suggestive, not definitive.

\section{References}

Bugelski, B. R., \& Scharlock, D. P. An experimental demonstration of unconscious mediation association. J. exp. Psychol., 1952, $44,334-338$.

Erickson, R. L. Differential effects of stimulus and response isolation in paired-associate learning. J. exp. Psychol., 1965, 69, 317-323.

Martin, R. B., \& Dean, S. J. Implicit and explicit mediation in paired-associate learning. J. exp. Psychol., 1964, 68, 21-27.

Peterson, M. J. Effects of delay intervals and meaningfulness on verbal mediating responses. J. exp. Psychol., 1965, 69, 60-66.

Peterson, M. J. Effects of knowledge of results on a verbal mediating response. J. exp. Psychol., 1963, 66, 394-398.

Russell, W. A., \& Storms, L. H. Implicit verbal chaining in pairedassociate learning. J. exp. Psychol., 1955, 49, 287-293.

Saltz, E., \& Newman, S. E. The von Restorff isolation effect: Test of the intralist association assumption. J. exp. Psychol., 1959 . $58,445-451$

Stein, L. S. Conscious mediating processes in a problem-solving task. J. exp. Psychol., 1966, 71, 212-217.

Underwood, B. J., \& Schulz, R. W. Meaningfulness and verbal learning. Philadelphia: Lippincott, 1960.

\section{Note}

1. This research was supported by Grant $\mathrm{MH} 07944$, National Institute of Mental Health, United States Public Health Service. 